\title{
Análise bibliométrica da produção acadêmica sobre Sustentabilidade nos Periódicos da Associação Nacional de Pós-Graduação e Pesquisa em Administração (ANPAD)
}

Bibliometric analysis of the academic production on Sustainability in the Periodicals of the National Association of Postgraduate and Research in Administration (ANPAD)

Análisis bibliométrico de la producción académica sobre Sostenibilidad en los Periódicos de la Asociación Nacional de Postgrado e Investigación en Administración (ANPAD)

Luiz Henrique Vieira da Silva Mestrando em Sustentabilidade e bolsista Capes Modalidade I, Pontifícia Universidade Católica de Campinas - PUC-Campinas, Brasil luiz.hvs@puccampinas.edu.br

\section{Samuel Carvalho De Benedicto} Professor Titular e Pesquisador do Centro de Economia e Administração da Pontifícia Universidade Católica de Campinas - PUC-Campinas, Brasil. samuel.benedicto@puccampinas.edu.br

Regina Márcia Longo

Professora e pesquisadora em dedicação integral da Pontifícia Universidade Católica de Campinas - PUC-Campinas, Brasil. regina.longo@puccampinas.edu.br 
RESUMO

A Sustentabilidade é um tema de destaque na Administração de Empresas, sobremaneira devido às transformações pelas quais a gestão empresarial passou do início do Século XX até os últimos anos, algo que tende a continuar. Por isso, buscou-se mensurar a produção bibliográfica relacionada à Sustentabilidade nas revistas em circulação ligadas à Associação Nacional de Pós-Graduação e Pesquisa em Administração (ANPAD), compreendendo o período entre 2004 e 2018. Fez-se uso de uma análise bibliométrica, a fim de quantificar o número de artigos publicados neste ínterim, bem como as instituições de origem dos autores, as palavras-chave e as abordagens de pesquisa utilizadas. Através dos 15 artigos encontrados, evidenciou-se que o tema tem uma regularidade nos periódicos da ANPAD, demonstrando a tendência da gestão sustentável das organizações.

PALAVRAS-CHAVE: Sustentabilidade; administração; análise bibliométrica.

\section{SUMMARY}

Sustainability is an outstanding topic in Business Administration, especially due to the changes that business management has undergone from the beginning of the 20th Century to the last years, which tends to continue. Therefore, we attempted to measure the bibliographical production related to Sustainability in the journals in circulation linked to the National Association of Postgraduate and Research in Administration (ANPAD), comprising the period between 2004 and 2018. A bibliometric analysis was used, in order to quantify the number of articles published in the meantime, as well as the institutions of origin of the authors, the keywords and the research approaches used. Through the 15 articles found, it was evidenced that the theme has a regularity in the ANPAD journals, demonstrating the trend of sustainable management of organizations.

KEY WORDS: Sustainability; management; bibliometric analysis.

\section{RESUMEN}

La Sostenibilidad es un tema destacado en la Administración de Empresas, sobre todo debido a las transformaciones por las que la gestión empresarial pasó del inicio del siglo XX hasta los últimos años, algo que tiende a continuar. Por eso, se buscó medir la producción bibliográfica relacionada a la Sustentabilidad en las revistas en circulación vinculadas a la Asociación Nacional de Postgrado e Investigación en Administración (ANPAD), comprendiendo el período entre 2004 y 2018. Se hizo uso de un análisis bibliométrico, a fin de cuantificar el número de artículos publicados en el ínterin, así como las instituciones de origen de los autores, las palabras clave y los enfoques de investigación utilizados. A través de los 15 artículos encontrados, se evidenció que el tema tiene una regularidad en los periódicos de la ANPAD, demostrando la tendencia de la gestión sustentable de las organizaciones.

PALABRAS CLAVE: Sostenibilidad; administración; análisis bibliométrico. 


\section{INTRODUÇÃO}

Do início do século XX até hoje, a Administração de Empresas passou por diversas transformações, agregou práticas e conhecimentos de outras áreas do saber e ampliou seu horizonte de atuação de maneira notável.

Em um conciso panorama histórico, é possível destacar algumas das principais contribuições da Academia aos estudos organizacionais (algo que, hoje, chamamos de Teoria das Organizações). Neste ponto, o intuito é contextualizar o leitor sobre as mudanças ocorridas ao longo das décadas, propostas no sentido de substituir a noção inicial de confiança irracional na produção eficiente e no maquinário industrial até chegarmos a uma etapa de elevada conscientização e responsabilidade socioambiental, que rompem com os muros das firmas e os interesses exclusivamente empresariais.

Taylor (1911) levou as ciências ao âmbito organizacional, através dos Princípios de Administração Científica; posteriormente, a Teoria Clássica da Administração, proposta por Fayol (1931), preconizava a eficiência e a produção nas organizações, por meio dos conceitos: planejamento, organização, comando, coordenação e controle.

A Escola das Relações Humanas (MAYO, 1933) centrou-se na interação das pessoas e na coordenação de suas atividades; a Teoria da Firma buscou diminuir os custos de transação (COASE, 1937) (WILLIAMSON, 1996); já, a Visão Baseada em Recursos, ficou responsável por inovar ao considerar os recursos e capacidades controlados pela empresa como sua vantagem competitiva (BARNEY, 1991) (BARNEY; WRIGHT; KETCHEN JR., 2001).

Chegamos, então, à Responsabilidade Social Corporativa (RSC) e à Criação de Valor Compartilhado (CVC), a partir de meados dos anos 1990 e, com maior força, após a virada do século. Os conceitos sugerem que, por estarem inseridas em uma determinada realidade, as organizações têm uma função social a cumprir com seus entornos, agindo a fim de "diminuir os impactos negativos no meio ambiente e comunidades, preservando recursos ambientais e culturais, respeitando a diversidade e reduzindo a desigualdade social” (CFA, 2014, s. p.) e para "reconectar o sucesso da empresa ao progresso social" (PORTER; KRAMER, 2011, s.p.), respectivamente.

Segundo Toffler (apud Tenório, 2004) e Zanin e Parisotto (2014), a esta consciência advém da sociedade pós-industrial, em que o aumento da qualidade de vida, a valorização do serhumano, o respeito ao meio-ambiente, a organização empresarial de múltiplos objetivos e a valorização das ações sociais são buscados, em detrimento do período industrial, em que o lucro e o sucesso econômico eram os únicos objetivos buscados.

A partir do exposto, é possível dizer que, atualmente, não relacionar a sustentabilidade ao contexto organizacional e à atuação empresarial tornou-se algo inconcebível. Sabe-se que as empresas contribuem para o crescimento econômico de um país ou de uma região, fornecem oportunidades de trabalho a milhões de pessoas, direta ou indiretamente, e, através de seus produtos, estão presentes nas casas e nas vidas de seus consumidores.

Entretanto, é latente que estas corporações também sejam responsáveis por prejuízos e/ou por externalidades negativas: em caso de má gestão financeira, podem trazer o desemprego a centenas de funcionários de uma só vez, ao falirem ou necessitaram de um grande programa de demissão voluntária; sem um devido tratamento de seus resíduos, correm o risco de 
poluírem o ar, a água e o solo, até mesmo de maneira irreversível, minando a possibilidade de uma relação sustentável entre a organização, seu entorno e as matérias-primas necessárias para a manutenção da produção.

Diante deste contexto, muitas empresas estão cada vez mais cientes de que suas atividades acarretam impactos significativos ao meio ambiente, que pode ser entendido como "o conjunto de condições, leis, influências e interações de ordem física, química e biológica, que permite, abriga e rege a vida em todas as suas formas" (BRASIL, 1981), bem como ao bemestar das sociedades e à manutenção da vida das futuras gerações.

De acordo com Almeida (2002), a empresa sustentável deve buscar a ecoeficiência em todas as suas ações e decisões, procurando produzir mais e com melhor qualidade, gerando menos poluição, utilizando menos recursos naturais. A partir disso, uma gama de estratégias apresenta-se a fim de evitar problemas e permitir que o desenvolvimento sustentável possa se tornar uma realidade.

As discussões sobre sustentabilidade e desenvolvimento sustentável ocorrem a partir da conversação entre várias dimensões. Sachs $(1993,2000)$, um dos autores mais influentes sobre a temática do desenvolvimento sustentável apresenta as seguintes dimensões: ambiental, cultural, social, espacial e econômica. Entretanto, no âmbito das empresas, as discussões sobre o desenvolvimento sustentável são pautadas pelo Tripé da Sustentabilidade (Triple Bottom Line): Ambiental, Econômico e Social, cunhado por Elkington (1997).

Tais elementos devem ser levados em consideração a fim de que alcancemos o conceito de desenvolvimento sustentável proposto no Relatório Brundtland, ou seja, "aquele que atende às necessidades do presente sem comprometer a possibilidade de as gerações futuras atenderem às suas necessidades" (ONU, 1987, s. p.).

Entretanto, a realidade brasileira, marcada por severas chagas históricas apresenta uma série de entraves que impedem o alcance deste ideal que, à primeira vista, parece utópico.

O mais recente estudo da Organização para a Cooperação e Desenvolvimento Econômico (OCDE), quando analisado sob a perspectiva social e econômica, demonstra que, no Brasil, a mobilidade social está comprometida: são necessárias nove gerações para que uma família ascenda da classe social mais baixa para a mais alta (OCDE, 2018). Segundo a mesma pesquisa, "a falta de mobilidade implica que muitos talentos são perdidos, o que prejudica o crescimento econômico potencial" (OCDE, 2018).

De acordo com o relatório da Comissão Econômica das Nações Unidas para os 33 países latinoamericanos e caribenhos (CEPAL), a região que compreende a América Latina e o Caribe é a mais desigual do mundo, com um coeficiente de Gini estimado em 0,5 (CEPAL, 2018). Destacase que, para este índice (utilizado para mensurar a desigualdade), quanto mais próximo de 1 , mais concentrada é a renda. 
Figura 1: Mapa indicando o Coeficiente de Gini a nível mundial (2014)

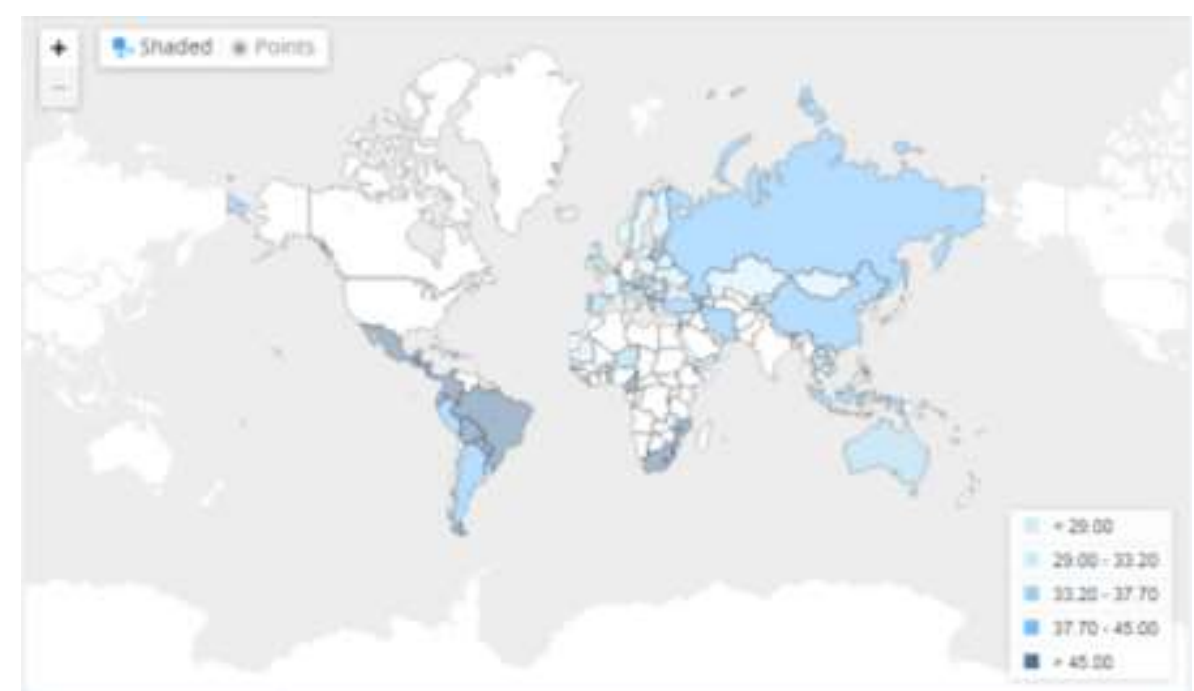

Fonte: World Bank (2014).

Segundo a mesma pesquisa, o Brasil tem pior taxa regional de conclusão do Ensino Fundamental II entre população mais pobre, além de apresentar problemas quanto ao acesso à Internet e desigualdades raciais, de gênero e étnicas (assim como outros países do continente).

A CEPAL também alerta para a presença desproporcional de negros no sistema carcerário do Brasil. Segundo a comissão, o número de pessoas privadas de liberdade cresceu $74 \%$ no país entre 2005 e 2012. O número de afrodescendentes presos é 1,5 vezes maior que o número de brancos (CEPAL, 2018); (ONUBR, 2018).

Quanto ao Índice de Desenvolvimento Humano (calculado através de indicadores de expectativa de vida ao nascer, educação e PIB per capita, recolhidos em nível nacional) há um cenário igualmente preocupante: apesar de melhorias significativas nos últimos anos (PNUD, 2015), o país ainda encontra-se em uma posição desconfortável no ranking geral, atrás de muitos países latino-americanos.

Tabela 1: Países latino-americanos no Índice de Desenvolvimento Humano (2014)

\begin{tabular}{|c|c|c|}
\hline Posição & País & Índice de Desenvolvimento Humano (IDH) \\
\hline 400 & Argentina & 0,836 \\
\hline 420 & Chile & 0,832 \\
\hline $52^{\circ}$ & Uruguai & 0,793 \\
\hline 600 & Panamá & 0,780 \\
\hline 670 & Cuba & 0,769 \\
\hline 690 & Costa Rica & 0,766 \\
\hline 710 & Venezuela & 0,762 \\
\hline 740 & México & 0,756 \\
\hline 750 & Brasil & 0,755 \\
\hline
\end{tabular}

Fonte: Elaborado pelos autores com base em PNUD (2015). 
Segundo a mesma pesquisa, o Brasil tem pior taxa regional de conclusão do Ensino Fundamental II entre população mais pobre, além de apresentar problemas quanto ao acesso à Internet e desigualdades raciais, de gênero e étnicas (assim como outros países do continente).

A CEPAL também alerta para a presença desproporcional de negros no sistema carcerário do Brasil. Segundo a comissão, o número de pessoas privadas de liberdade cresceu $74 \%$ no país entre 2005 e 2012. O número de afrodescendentes presos é 1,5 vezes maior que o número de brancos (CEPAL, 2018); (ONUBR, 2018).

Ademais, do ponto de vista ambiental, o Brasil aparece entre os principais poluidores mundiais, apresentando números de poluição industrial em solos, na água e no ar preocupantes, sobremaneira na emissão de gases que contribuem para o efeito estufa e para o aquecimento global, como o gás carbônico $\left(\mathrm{CO}_{2}\right)$, ainda que a porcentagem da participação brasileira na poluição mundial seja muito inferir à de países como China e EUA (ONUBR, 2018).

Dessa forma, depreende-se que caberia especialmente aos Estados, através de seus governos nas mais variadas esferas e atribuições, lidar com estas questões, dada a complexidade e a capilaridade do tema apresentado.

Entretanto, segundo Wieczynski e Andreolla (2005, p. 14), sob a ótica do Estado e das ações governamentais, por muito tempo vigorou uma lógica paternalista, assistencialista e clientelista e, do ponto de vista das organizações do terceiro setor, há, muitas vezes,

...falta de conhecimentos técnicos e teóricos em gestão social por parte da maioria dos gestores das ONGs e por falta de recursos financeiros, não são postos em prática ou não conseguem ser concluídos como planejados.

$\mathrm{Na}$ brilhante obra "Muito além da Economia Verde", Abramovay (2012) realiza um paralelo entre dois pensamentos: o liberal, sustentado por autores como Hayek e os que defendem a teoria da firma; e à esquerda, impulsionados pelo marxismo e os pensadores que derivam desta corrente. Para surpresa do leitor, apesar de antagônicos, convergem para o mesmo ponto: por razões distintas, ambos admitem que as empresas têm como única função lucrar, fazendo de iniciativas como a responsabilidade social corporativa algo meramente "superficial, enganosa, cosmético" (ABRAMOVAY, 2012, p. 135).

Contudo, este autor defende a reaproximação entre o mercado e a sociedade, entre a ética e a economia: os mercados não devem ser observados como entidades mágicas, dotadas de vontade própria e imprevisível; ao contrário, é necessário que a Ciência compreenda que eles não são autônomos e nem independentes, mas se encontram inseridos em comunidades, sociedades, sujeitos às influências, aos desejos e aos demais desdobramentos destes meios, evidenciando que "a incorporação aos próprios mercados de valores ambientais, éticos ou mesmo de equidade social" deve ser uma realidade (ABRAMOVAY, 2012, p. 137).

Nesse sentido, Abramovay (2012, p. 22) enfatiza de forma assertiva que a nova economia precisa ser encarada

...não pelo monopólio estatal sobre as decisões empresariais nem pela abolição dos mercados, mas, ao contrário, no âmbito de uma economia descentralizada na qual os mercados desempenham papel decisivo, ainda que, evidentemente, não exclusivo. 
Perante esta situação, entre os dias 25 e 27 de setembro de 2015, na sede da ONU em Nova Iorque, aconteceu a Cúpula das Nações Unidas sobre o Desenvolvimento Sustentável. No encontro, todos os países da ONU definiram os novos Objetivos de Desenvolvimento Sustentável (ODS), que consistem em 17 objetivos e 169 metas que deverão ser atingidos até o ano de 2030, como parte de uma nova agenda de desenvolvimento sustentável.

Neste documento, a integração entre os governos, as organizações não governamentais, as empresas e a sociedade civil adquire papel fundamental e crucial para o êxito de todos os pontos que foram propostos. Dentre os Objetivos e Metas, o termo "empresa" é mencionado diversas vezes, como disposto a seguir:

- $\quad 8.3$ promover políticas orientadas para o desenvolvimento, que apoiem as atividades produtivas, a geração de emprego decente, o empreendedorismo, a criatividade e inovação, e incentivar a formalização e o crescimento das micro, pequenas e médias empresas, inclusive por meio do acesso a serviços financeiros;

- $\quad 9.3$ aumentar o acesso das pequenas indústrias e outras empresas, particularmente em países em desenvolvimento, aos serviços financeiros, incluindo crédito acessível e propiciar sua integração em cadeias de valor e mercados;

- $\quad 12.6$ incentivar as empresas, especialmente as empresas grandes e transnacionais, a adotar práticas sustentáveis e a integrar informações sobre sustentabilidade em seu ciclo de relatórios;

○ $\quad 17.17$ incentivar e promover parcerias públicas, público-privadas, privadas, e com a sociedade civil eficazes, a partir da experiência das estratégias de mobilização de recursos dessas parcerias.

Também, a Agenda 2030 enfatiza a participação empresarial na promoção da "mudança de consumo e produção não sustentáveis", "mobilização de recursos financeiros, bem como o reforço das capacidades e a transferência de tecnologias ambientalmente adequadas para os países em desenvolvimento em condições favoráveis", "desenvolvimento internacional" e impulso "da produtividade, do crescimento econômico inclusivo e da criação de emprego" (NAÇÕES UNIDAS NO BRASIL, 2015).

Sendo assim, a sustentabilidade tornou-se cada vez mais presente no ambiente empresarial. A partir do exposto, o presente estudo realizou uma análise bibliométrica nos periódicos em circulação indicados pela Associação Nacional de Pós-Graduação e Pesquisa em Administração - ANPAD, instituição fundada em 1976 e que congrega programas de pós-graduação stricto sensu, representando os interesses das instituições filiadas junto à opinião pública e atuando como órgão articulador dos interesses dos programas perante a comunidade científica e os órgãos governamentais responsáveis pela gestão da educação e desenvolvimento científico e tecnológico em nosso país.

A seguir, há uma breve descrição dos periódicos escolhidos para a realização do presente trabalho.

De acordo com o sítio oficial da ANPAD, a revista BAR - Brazilian Administration Review é um periódico eletrônico editado em língua inglesa para atender a necessidade de ampliar e internacionalizar a difusão do conhecimento em administração produzido pela comunidade científica brasileira. É uma revista eletrônica com escopo internacional em termos de temas, 
público-alvo e Conselho Editorial, classificada pelo Sistema Qualis, da Coordenação de Aperfeiçoamento de Pessoal no Nível Superior - Capes, como Revista "A2", em uma escala que varia, decrescentemente, entre A1, A2, B1, B2, B3, B4, B5 e C.

Por sua vez, a RAC - Revista de Administração Contemporânea é voltada à comunidade acadêmica, professores, pesquisadores e estudantes, sendo uma das mais tradicionais revistas científicas de administração do país. É uma revista de amplo escopo em termos de temas, público e autores e, assim como a BAR, também é classificada pelo Sistema Qualis como Revista "A2". Atualmente, a RAC é veiculada apenas eletronicamente.

\section{OBJETIVOS}

Com o uso de uma pesquisa bibliométrica, pretende-se ampliar o conhecimento acerca do tema da Sustentabilidade na produção acadêmica brasileira nos Periódicos em circulação da ANPAD, a fim de relacionar o crescimento da procura por soluções sustentáveis nas organizações privadas à crescente popularização do tema.

\section{MÉTODO DE ANÁLISE}

De acordo com Soares, Picolli e Casagrande (2018, p. 334-335) a pesquisa bibliométrica tem como principal característica "o processo de mensuração, que pode abranger dimensões como número de autores, número de artigos, número de citações, número de coautorias, número de revistas, número de temas, frequência de cooperação de grupos, instituições ou países e obediência às leis de bibliometria".

Para tanto, fez-se uso da Lei de Bradford, que "investiga as distribuições de frequência do número de artigos publicados por periódicos de determinado tema/área" (SOARES; PICOLLI; CASAGRANDE, 2018, p. 321).

As referidas revistas foram escolhidas porque o intuito desta investigação foi analisar a correlação entre a sustentabilidade e as organizações e a ANPAD representa, atualmente, um referencial teórico de prestígio para a pesquisa acadêmica em Administração.

No sítio oficial do órgão, há quatro periódicos listados, a saber: BAR - Brazilian Administration Review; RAC - Revista de Administração Contemporânea; TAC - Tecnologias de Administração e Contabilidade; e, finalmente, RAC - Eletrônica.

Para a análise, consideramos apenas as duas primeiras revistas, uma vez que a TAC Tecnologias de Administração e Contabilidade e a RAC - Eletrônica são publicações descontinuadas: a TAC foi lançada em janeiro de 2011 e sua publicação foi encerrada em dezembro de 2016 e a RAC-Eletrônica foi lançada em janeiro de 2007 e sua publicação foi encerrada em janeiro de 2009. Porém, com a decisão da ANPAD de incorporar a TAC à RAC, as submissões de Artigos Tecnológicos e de Casos para Ensino passam a ser recebidas pela RAC, portanto, entendemos que não houve perda científica na elaboração deste estudo.

Para encontrar o material, utilizamos como termos de pesquisa: "Sustainable" ou "Sustainability" para os títulos na BAR - Brazilian Administration Review, já que a revista tem suas publicações realizadas em inglês e "Sustentabilidade" ou "Sustentável" para os títulos na RAC - Revista de Administração Contemporânea, que tem artigos publicados em Língua Portuguesa. 
Para Daly (1996), "sustentabilidade" é um termo de que todos gostam, mas que, ao mesmo tempo, muitos não conhecem exatamente seu sentido ou seu conceito. Sendo assim, a análise bibliométrica poderá evidenciar como esta temática está sendo abordada nestes periódicos de grande relevância para a administração de empresas.

O período escolhido compreendeu o ínterim entre 2004 e 2018, tomando como ponto de partida o ano de início das publicações na BAR - Brazilian Administration Review.

Destaca-se, que a análise disposta abaixo, nos resultados, considerou somente a publicação de artigos científicos, excluindo notas bibliográficas, resenhas e afins.

Os artigos foram catalogados utilizando-se o software Microsoft Excel, para tabulação e criação do gráfico e dos quadros e tabelas.

\section{RESULTADOS}

Os resultados levam em consideração um levantamento feito com base nos 6 artigos encontrados na BAR - Brazilian Administration Review e nos 9 artigos encontrados na RAC Revista de Administração Contemporânea. Nesta análise, foram dispostos os seguintes dados: ano da publicação, autores, instituição dos autores, palavras-chave e o tipo do estudo.

O gráfico da Figura 2 apresenta a distribuição dos artigos publicados entre os anos de 2004 e 2018.

Figura 2: Quantidade de artigos publicados por ano (2004 - 2018)

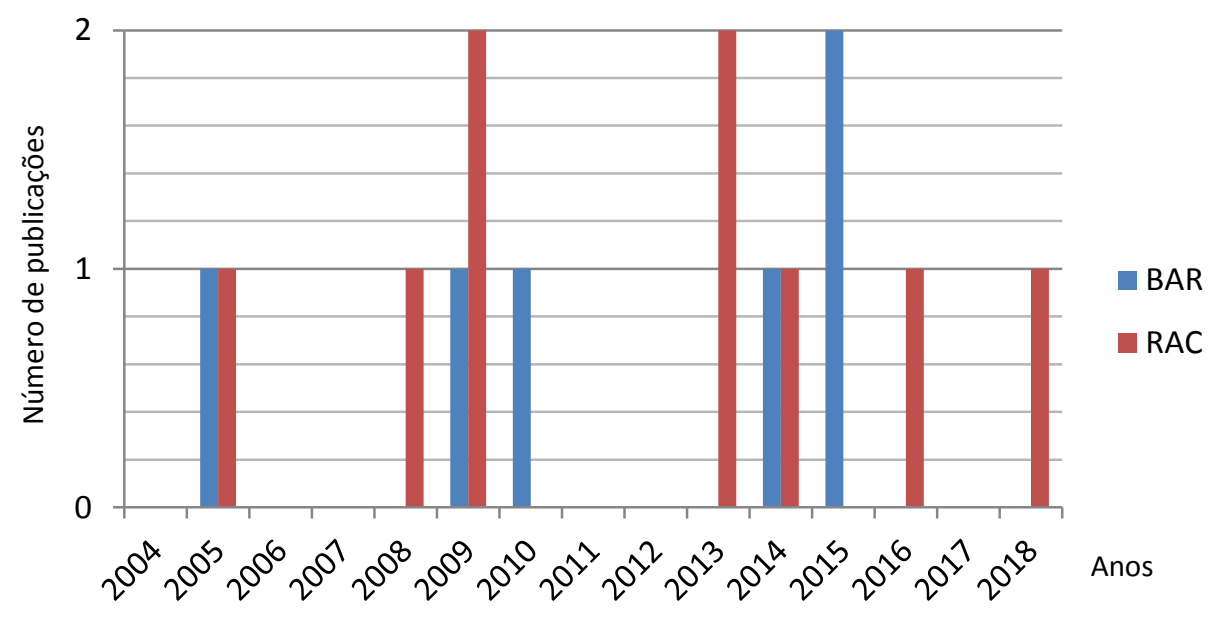

No que diz respeito ao número de instituições de ensino superior (IES) envolvidas, através da vinculação feita pelos autores, chegou-se ao número de 18 instituições, sendo 17 brasileiras e apenas 1 estrangeira, localizada no Canadá. O Quadro 1 compila estas informações. 
Quadro 1: Instituições de Ensino vinculadas pelos autores

\begin{tabular}{|c|c|}
\hline Instituição & Sigla \\
\hline Centro Universitário das Faculdades Metropolitanas Unidas & FMU \\
\hline Centro Universitário FEI & FEI \\
\hline École des Hautes Études Commerciales de Montréal & FGV \\
\hline Fundação Getulio Vargas & IFECTP \\
\hline Instituto Federal de Educação, Ciência e Tecnologia do Pará & UNIFOR \\
\hline Universidade de Fortaleza & USP \\
\hline Universidade de São Paulo & UNIVALI \\
\hline Universidade do Vale do Itajaí & UEC \\
\hline Universidade Estadual do Ceará & UFPB \\
\hline Universidade Federal da Paraíba & UFJF \\
\hline Universidade Federal de Juiz de Fora & UFMG \\
\hline Universidade Federal de Minas Gerais & UFSM \\
\hline Universidade Federal de Santa Maria & UFV \\
\hline Universidade Federal de Viçosa & UFES \\
\hline Universidade Federal do Espírito Santo & UFP \\
\hline Universidade Federal do Paraná & UNINOVE \\
\hline Universidade Nove de Julho & FURB \\
\hline Universidade Regional de Blumenau & \\
\hline
\end{tabular}

A Figura 3 apresenta, das instituições citadas, as que mais tiveram artigos aprovados no período estudado. Foram elas: Universidade Federal do Paraná (UFPR), com o maior número de publicações, seguida das Universidades de Fortaleza (UNIFOR), Federal de Minas Gerais (UFMG) e Federal do Espírito Santo (UFES), com duas publicações cada.

Figura 3: Produção das IES que mais publicaram entre 2004 e 2018
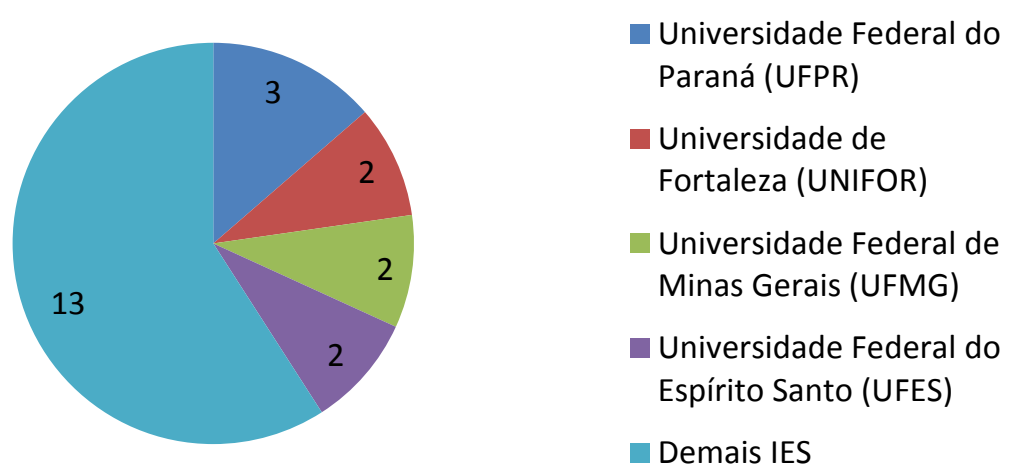

Já, na Figura 4, as Instituições de Ensino Superior vinculadas aos autores foram organizadas por regiões brasileiras, sendo a região Sudeste a que dispõe do maior número de artigos publicados no intervalo de tempo analisado. 
Figura 4: Produção por região das IES que mais publicaram entre 2004 e 2018

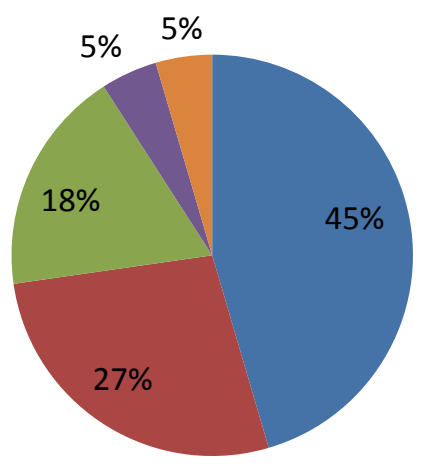

- Sudeste

- Sul

Nordeste

Norte

Centro-Oeste

Internacional

Ressalta-se que, em ambos os quadros dispostos acima, se somados, os totais ultrapassam os 15 artigos utilizados na análise. A resposta para isso é que muitos artigos têm dois ou mais autores.

Verificar as palavras-chave escolhidas pelos autores também constitui um processo importante da análise bibliométrica. A partir delas, é possível entender traços dos objetivos dos artigos e, especialmente, das áreas teóricas nas quais se encontram. Na Tabela 2, estão dispostas todas as palavras-chave encontradas nos artigos, bem como suas respectivas quantidades de aparição.

Tabela 2: Palavras-chave utilizadas nos artigos aprovados entre 2004 e 2018

\begin{tabular}{cl}
\hline Palavra-chave & Citações \\
\hline Sustainability/Sustentabilidade & 8 \\
\hline Responsabilidade Social Corporativa & 2 \\
\hline Administração de stakeholders & 2 \\
\hline Bibliometria & 2 \\
\hline Sustentabilidade ambiental & 2 \\
\hline Sustainability indicators & 1 \\
\hline Institutional logic & 1 \\
\hline Sharing economy & 1 \\
\hline Bicilcetar Project & 1 \\
\hline Brazilian higher education & 1 \\
\hline Higher education institution & 1 \\
\hline Disclosure & 1 \\
\hline Learning practices & 1 \\
\hline Network & 1 \\
\hline Small enterprises & 1 \\
\hline Business practices & 1 \\
\hline Grounded theory & 1 \\
\hline Brazilian business context & 1 \\
\hline Natural capital & 1 \\
\hline Depletion of natural resources & 1 \\
\hline Environmentally balanced output growth & 1 \\
\hline Tourism & 1 \\
\hline Cluster & 1 \\
\hline
\end{tabular}




\begin{tabular}{|c|c|}
\hline Local development & 1 \\
\hline Competitiviness & 1 \\
\hline Inovação em processos & 1 \\
\hline Cadeia de fornecimento & 1 \\
\hline Reciclagem & 1 \\
\hline Logística reversa & 1 \\
\hline Estratégia & 1 \\
\hline Discurso da sustentabilidade & 1 \\
\hline Materiais visuais & 1 \\
\hline Análise sócio-hermenêutica & 1 \\
\hline Cognição & 1 \\
\hline Mapas cognitivos & 1 \\
\hline Valor sustentável & 1 \\
\hline ISE & 1 \\
\hline Ensino e pesquisa em administração & 1 \\
\hline Teoria institucional & 1 \\
\hline Legitimação do conhecimento & 1 \\
\hline Análise de redes sociais & 1 \\
\hline Empreendedorismo sustentável & 1 \\
\hline Criação de valores & 1 \\
\hline Desenvolvimento sustentável & 1 \\
\hline Visão baseada em recursos naturais & 1 \\
\hline Gestão de recursos humanos & 1 \\
\hline Vantagem competitiva sustentável & 1 \\
\hline
\end{tabular}

A partir disso, evidenciou-se que, nos estudos organizacionais, a sustentabilidade ficou confinada somente à sua dimensão ambiental, pois "o termo sustentabilidade geralmente é usado como o equivalente de salvaguardar a natureza" (LÁSZLÓ, 2008), ainda que seja muito mais amplo.

Finalmente, no período estudado, as publicações passaram por uma análise em relação à metodologia utilizada na abordagem (qualitativa, quantitativa ou genérica/mista), conforme disposto na Figura 5.

Figura 5: Abordagens utilizadas nos artigos aprovados entre 2004 e 2018

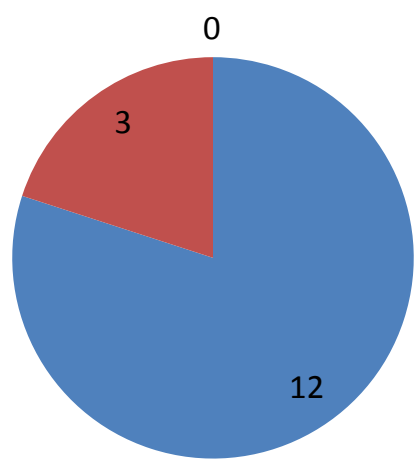

Qualitativa

- Genérica ou Mista

Quantitativa

\section{CONSIDERAÇÕES FINAIS}

A sustentabilidade é um tema de destaque na Administração de Empresas, sobremaneira 
devido às transformações pelas quais a gestão empresarial passou do início do Século XX até atualmente.

Isto ficou evidenciado na quantidade de artigos encontrados, de maneira bastante uniforme em todos os anos analisados na pesquisa. Se somados às notas bibliográficas e resenhas encontradas, chegaríamos a um número ainda mais significativo.

A Instituição de Ensino Superior com o maior número de publicações foi a Universidade Federal do Paraná, que conta com campi em Curitiba e outras cidades do litoral e do interior do estado. Elencando todas as palavras-chave dos artigos, detectou-se uma predileção por temas ligados à área ambiental, enquanto que as outras duas vertentes do Tripé de Elkington (1997) não foram tão contempladas, ainda que registrem uma quantidade considerável de publicações nas revistas.

Diante disso, detectou-se um vácuo de conhecimento que, se preenchido, poderia auxiliar em processos referentes a Inovação nas indústrias e Pesquisa e Desenvolvimento, tratando-se do pilar Econômico da sustentabilidade, bem como a políticas de Recursos Humanos, no caso do pilar Social da sustentabilidade, por exemplo.

Evidenciou-se, finalmente, que a grande maioria dos artigos utilizou uma abordagem qualitativa, enquanto que nenhum(a) autor(a) optou por uma abordagem exclusivamente qualitativa. Isso se deve ao fato de que a opção por estudos de casos ou a análise de relatórios de sustentabilidade de organizações foram métodos de coleta de dados bastante frequentes.

Depreende-se, portanto, que sustentabilidade e administração caminham juntas, levando-nos a um futuro próximo em que a atividade empresarial possa contemplar questões inerentes ao desenvolvimento sustentável e à melhoria da qualidade de vida no planeta. $E$, para que a sustentabilidade não se torne algo trivial, é necessário compreendê-la como conceito e destacar sua aplicabilidade em diversos cenários e sob suas várias vertentes.

\section{AGRADECIMENTO}

O presente trabalho foi realizado com apoio da Coordenação de Aperfeiçoamento de Pessoal de Nível Superior - Brasil (CAPES) - Código de Financiamento 001.

\section{REFERÊNCIAS BIBLIOGRÁFICAS}

ABRAMOVAY, Ricardo. Muito além da Economia Verde. São Paulo: Ed. Abril, 2012.

ALMEIDA, Fernando. O bom negócio da sustentabilidade. Rio de Janeiro: N. Fronteira, 2002.

BARNEY, Jay. B. Firm resources and sustained competitive advantage. Journal of Management, 17: 99-120, 1991.

BARNEY, Jay; WRIGHT, Mike; KETCHEN JR., David J. The resource-based view of the firm: Ten years after 1991. Journal of Management 27 (2001) 625-641, 2001.

BRASIL. Lei no 6.938, de 31 de agosto de 1981. Dispõe sobre a Política Nacional do Meio Ambiente, seus fins e mecanismos de formulação e aplicação, e dá outras providências.

CEPAL. A ineficiência da desigualdade. Síntesis (LC/SES.37/4), Santiago, 2018. Disponível em: <https://repositorio.cepal.org/bitstream/handle/11362/43567/1/S1800302_es.pdf>. Acesso em: 05 abr. 2019. 
CFA. Responsabilidade Social empresarial. Disponível em: http://www.cfa.org.br/acoescfa/artigos/usuarios/responsabilidade-social-empresarial. Acesso em: 14/02/2017.

COASE, Ronald H. The nature of the firm. Economica, v.4, 16, p.386-405, 1937.

DALY, Herman. Beyond growth. Boston: Beacon Press, 1996.

ELKINGTON, John. Cannibals with forks - Triple bottom line of 21st century business. Stoney Creek, CT: New Society Publishers, 1997.

FAYOL, Henri. Administration industrielle et générale. Paris: Dunod, 1931.

LÁSZLÓ, Ervin. Entrevista concedida à revista Página 22. Out. 2007.

MAYO, Elton. The Social Problems of an Industrial Civilization. Routledge \& Kegan Paul, London, 1933.

NAÇÕES UNIDAS NO BRASIL. Transformando Nosso Mundo: A Agenda 2030 para o Desenvolvimento Sustentável. Disponível em: <https://nacoesunidas.org/pos2015/agenda2030/>. Acesso em: 23 fev. 2019.

OCDE. A Broken Social Elevator? How to Promote Social Mobility. OECD Publishing, Paris. 2018. Disponível em: <https://doi.org/10.1787/9789264301085-en>. Acesso em: 15/06/2018.

ONU. Report of the World Commission on Environment and Development. 1987. Disponível em: <http://www.un.org/documents/ga/res/42/ares42-187.htm>. Acesso em: 17/03/2019.

ONUBR. América Latina e Caribe é região mais desigual do mundo, revela comissão da ONU. 2018. Disponível em: $<$ https://nacoesunidas.org/america-latina-e-caribe-e-regiao-mais-desigual-do-mundo-revela-comissao-da-onu/>. Acesso em: 05 abr. 2019.

ONUBR. Conferências de meio ambiente e desenvolvimento sustentável: um miniguia da ONU. Disponível em: $<$ https://nacoesunidas.org/conferencias-de-meio-ambiente-e-desenvolvimento-sustentavel-miniguia-da-onu/>. Acesso em: 21 mar. 2019.

ONUBR. Emissões de dióxido de carbono sobem pela 1a vez em quatro anos, diz agência da ONU. 2018. Disponível em: <https://nacoesunidas.org/emissoes-de-dioxido-de-carbono-sobem-pela-1a-vez-em-quatro-anos-diz-agenciada-onu/>. Acesso em: 08 abr. 2019.

PNUD (Programa das Nações Unidas para o Desenvolvimento). Relatório de Desenvolvimento Humano: O Trabalho como Motor do Desenvolvimento Humano. 2015. Disponível em:

<http://www.br.undp.org/content/brazil/pt/home/idh0/rankings/idh-global.html>. Acesso em: 05 abr. 2019

PORTER, Michael; KRAMER, Mark. Criação de valor compartilhado. Harvard Business Review Brasil. 2011. Disponível em: https://hbrbr.uol.com.br/criacao-de-valor-compartilhado/. Acesso em: 12 abr. 2019.

SACHS, Ignacy. Caminhos para o Desenvolvimento Sustentável. Rio: Garamond, 2000.

SACHS, Ignacy. Estratégias de transição para o século XXI. In: BURSZTYN, M. Para Pensar o Desenvolvimento Sustentável. São Paulo: Brasiliense, p. 29-56, 1993.

SOARES, Sandro Vieira; PICOLLI, Icaro Roberto Azevedo; CASAGRANDE, Jacir Leonir. Pesquisa Bibliográfica, Pesquisa Bibliométrica, Artigo de Revisão e Ensaio Teórico em Administração e Contabilidade. Administração: Ensino e Pesquisa, [S.I.], v. 19, n. 2, p. 308-339, maio 2018. ISSN 2358-0917. Disponível em: <https://raep.emnuvens.com.br/raep/article/view/970>. Acesso em: 20 fev. 2019.

TAYLOR, Frederick W. Principles of Scientific Management. New York: Harper \& Row, 1911.

TENÓRIO, Fernando Guilherme. (Org.). Responsabilidade social empresarial: teoria e prática. FGV: Rio de Janeiro, 2004. 
WIECZYNSKI, Marineide; ANDREOLLA, Elisiane. As ferramentas da gestão social utilizada pelas organizações que prestam serviços sociais à comunidade e pertencem à microrregião do extremo oeste do Estado de Santa Catarina. Revista Virtual Textos \& Contextos, n.4, 2005.

WILLIAMSON, Oliver Eaton. Economics and organization: a primer. California Management Review, v.38, n.2, p.131-146, 1996.

WORLD BANK. GINI index (World Bank estimate). 2014. Disponível em: <https://data.worldbank.org/indicator/SI.POV.GINI/?view=map\&year=2014\&year_high_desc=false>. Acesso em: 05 abr. 2019. 